\title{
BASILECTAL FEATURES OF BAHAMIAN CREOLE ENGLISH
}

\author{
Janet L. Donnelly \\ Humanities Division, The College of The Bahamas
}

Although Bahamian Dialect appears to be a dialect of English, it is actually more a creole - though it has decreolized over the years. Its overall grammar is systematically different from that of standard English and yet the two share many of the same features. This serves to enhance the illusion that the two are different dialects of the same language.

All of this - two distinct systems masquerading as one - presents particular problems to young students faced with learning to read and write in Standard English when, in fact. they speak a different language. It also presents specific challenges to teachers in their approach to the language arts. They must cope with interference problems arising from their students' mother tongue (Bahamian Dialect) while they are acquiring the school language (Standard Bahamian English).

A clear and accessible description of the grammar of Bahamian Dialect is needed to assist teachers in their task and to facilitate students in their mastering of the Standard. This paper is an attempt to start that process - a step towards just such a description. The ultimate goal is to provide not only a description but a deeper appreciation and even celebration of Bahamian Dialect.

\section{INTRODUCTION}

The Bahamas consists of over 700 islands, rocks and cays - but, in truth, no more than a few dozen or so of these islands and cays bear any settlements. In fact, the overall population is relatively low when compared to neighboring island nations. According to the official 1990 census (School Atlas, Bahamas, 1992) the total population was 254,685 with the majority resident in Nassau/New Providence $(171,542)$ followed by Freeport/Grand Bahama $(10,061)$ and then scattered in varying proportions throughout the remaining Family Islands. Thus, while the population density for the entire Bahamas is 47 persons per square mile, it in fact varies from as high as 2,144 in New Providence to as low as 2 in Acklins, one of the larger islands in the southeastern quadrant.

In land mass The Bahamas is just 5,383 square miles - slightly larger in area than Jamaica but far smaller than Cuba or Hispaniola, which border it to the south. Yet in total area, taking in territorial waters, The Bahamas is really quite extensive, its total area nearly as large as the entire Lesser Antilles. 
Topographically, the islands of The Bahamas tend to be low-lying (rarely exceeding 150 feet - the highest point in the entire chain being 206 feet on Cat Island), consisting of lime rock and sandy soil. The vegetation is not as naturally lush as in most of the islands in the Caribbean; nonetheless, with cultivation, foliage flourishes. What The Bahamas has truly been blessed with in terms of natural features is an abundance of beautiful sandy beaches and exquisitely clear, aquamarine water.

Although The Bahamas happens to be the place where Columbus and his expedition made their landfall in the New World in 1492, it took about one and a half centuries before any European settlement took place. These islands were lacking in the gold and other resources sought by the Spanish and when the islands were eventually claimed it was, for the most part, by the British.

The Arawak Indians who originally populated the islands now known as The Bahamas were wiped out by the ensuing years of enslavement in the gold mines of Haiti. It would take another group of people (who were also enslaved) to eventually repopulate these same islands and give them a language and culture uniquely "Bahamian".

Essentially, Africans arrived with the first wave of Europeans, via Bermuda. as early as 1656 when according to Albury (1975) .... "some troublesome slaves, native Bermudians and all the free negroes were sent into exile at Eleuthera". From that point there was a continuous increase of Africans brought in, with notable surges at key points. The records are not entirely clear as to how many blacks were slaves and how many were free men, how many were imported directly from Africa (and from which part) and how many were creole. However, a notable drop in importations can be observed in the early nineteenth century following the abolition of the slave trade in 1807.

Saunders (1985) says, "After the abolition of the slave trade the number of slave imports virtually ceased". Some slave ships were intercepted by the British and the Africans were freed and put ashore, mostly in New Providence, the island Nassau occupies. A few slave owners took their slaves with them to other places, such as Cuba and Trinidad, but mostly the population stabilized or "creolized" as fewer Africans entered The Bahamas.

It is estimated that over $90 \%$ of the people of The Bahamas can trace their roots-or part of their roots-back to Africa, I say "estimated" because no breakdown is made along racial lines in modern-day census taking. So while whites originally outnumbered blacks there is clearly a black majority today. Naturally it is represented over all the social strata as is the white minority. 
Over the years movement has occurred among the various islands. For many years the primary means of travel was the native sloop. A good number of Bahamians depended on the sea for their livelihood as seamen, fishermen or traders. Eventually motorized boats, particularly the mailboats, superseded the sailing sloop. And then, of course, came the airplane. As transportation has changed, so have the destinations. For example, when Abaconians went everywhere by sloop, Green Turtle Cay was the centre of commerce for the Abacos. Now with planes and cars prevailing, Marsh Harbour is the hub for that area.

It should be noted that television is a fairly recent phenomenon on the more far flung Family Islands. Only in the last 10 years has electrification been extended to these islands (some island settlements still remain dependent on generators and kerosene refrigerators while waiting for eventual electrification). Over the years satellite dishes have sprouted up like banana trees behind the homes of some of the more affluent Family Islanders; electrification has only increased the number of dishes in use. Private telephone lines have also now reached most of these islands. Again, this is a recent development and I mention both for a reason. One has to ponder the potential impact of both television and the telephone (as well as their previous absence).

The Bahama islands extend from Walker's Cay in the north to Great Inagua in the south, and from Bimini in the west to San Salvador in the east. Great expanses of water stand between many islands and, until recently, fairly thick bush and rough terrain separated settlements. Given the years of isolation resulting from these physical obstacles and given the little communication that did take place with other islands (or even settlements on the same island). It is striking that language features are as uniformly distributed throughout The Bahamas as they are. Even those features which are regarded as more typical of the southeastern islands can be found in other areas of The Bahamas, even in Nassau itself. Of course it can be argued that all Nassauvians are displaced Family Islanders (though that is not quite the case). Nevertheless there are only a few features which might be regarded as more regional in nature. Most of the features which distinguish the basilect from the acrolect occur in all parts of The Bahamas.

I have given only a brief description of these islands here. For those of you wishing more details there are many excellent sources, among them Albury (1975), Capron and Saunders. But from what I have covered it should be evident that the language and culture of The Bahamas reflect a fusion of mostly British and African influences resulting from years of British rule and eventual independence (1973). It is the language that resulted which this presentation addresses - a creole not unlike many other Englishbased creoles around the Caribbean, which were also forged under somewhat similar circumstances. There is, of course, much socio-economic background which I must necessarily omit here. 


\section{PURPOSE OF THE PAPER}

The purpose of this paper is to describe some of the more basilectal features of Bahamian and, by so doing, to provide a frame for further study and applications. I say some of the more basilectal features because it would be too ambitious to tackle all of them in a paper of this length. But my wish is to move toward a more comprehensive description which will make the rules of the basilect more accessible not only to linguists/creolists but also to the speakers - as well as those involved in the teaching of the language arts. Indeed, one of the most compelling reasons for providing a clear and simple description of Bahamian is that such a description will enable us to facilitate the teaching of the language arts at both the primary and secondary levels. A handbook for teachers - similar to Pollard's From Jamaican Creole to Standard English (1993) - is very much needed for the Bahamian national curriculum.

\section{REVIEW OF THE LITERATURE}

\section{Dictionary of Bahamian English}

This is not to say that descriptions have not been provided thus far. Excellent work has been carried out by a number of people. Holm, with Shilling, (1982) describe a few of the more distinctive syntactic features of Bahamian, particularly those concerning the verb phrase, in the Introduction to the Dictionary of Bahamian English. Further details are noted under individual citations in the text. Additionally, Holm (1988) gives numerous examples from Bahamian in his Pidgins and Creoles, (Vol. I) and has written articles with specific references to Bahamian (1983, 1980).

Shilling (1978) focuses on a few key features of Bahamian syntax in her unpublished doctoral dissertation. Crucial areas detailed are the distribution of the copula, verbal negation and negative concord, pronoun copying, deletion of dummy subjects and topicalization. Albury (1981) looks particularly at past forms in Black Bahamian English in her masters thesis. She further explores the use of past forms and their functions in a paper presented at the SCL conference in Trinidad (Lawlor, 1986). Major (1993) gives an overview of many of the phonological and morpho-syntactoc features of Bahamian English creole in her masters paper in which she looks at dialect interference in college writing.

This would seem to provide any interested party with an ample description of Bahamian, so what's the need of further material? What's the problem? There are actually several. First, the dictionary is (most unfortunately) out of print and, for complex reasons, unlikely to be reprinted. Naturally, there is quite a demand for it in The Bahamas, but with its small population any financial return is unlikely. Furthermore, it would be desirable to revise it and add to it, but that in itself is no small task. So we are left with a fairly limited number of copies available. 


\section{Unpublished Dissertations}

Another problem lies in the difficulty of accessing unpublished dissertations (Shilling, Albury and Major), all of which are available in the special collection room of the library at The College of The Bahamas. At the moment the only way to do this is by physically visiting the library, though at some time in the future these will all be available over the Internet. But even when they become more readily available, how "accessible" will they be to someone not directly involved in creolinguistics? This is a problem in itself and it should be addressed if appropriate applications are to take place.

Furthermore, there are areas which need additional investigation and statistical analysis so as to provide a more accurate description of the distribution of the basilectical features. Fortunately, there are a number of former students of The College who have pursued (or are pursuing) higher degrees in linguistics and who have a keen interest in documenting all aspects of Bahamian English creole.

\section{Origin of Bahamian Dialect}

As Holm says in the Introduction to the Dictionary of Bahamian English (1982), "Like most other creole languages, Bahamian English arose from a collision of languages, and cultures under the social conditions of slavery". Bahamian - like other Caribbean creoles - is definitely a meld of languages. Its lexicon may be European (i.e., English in this case) but its grammar is essentially African, though superficially it appears to the English.

Bahamian Creole English (or Bahamian English Creole) is popularly known in The Bahamas as Bahamian Dialect. BCE/BD still exhibits a number of basilectical features, despite years of decreolization. Some of these features are pervasive throughout the Bahamian archipelago while others tend to be more restricted to the southeastern islands, which have been historically more removed - physically, economically and socially - from the mainstream.

Historically, these same islands differed demographically from many of the other islands of The Bahamas in that blacks outnumbered whites 9:1. Lawlor drew attention to this in her paper at the SCL conference in Nassau (1988), noting that this would have been the most favorable ratio (compared to other parts of The Bahamas) for maintaining a creole.

Within The Bahamas there exists a language continuum ranging from the basilectal through mesolectal to acrolectal, each variety impacting on the others. A good many Bahamians speak a more mesolectal variety (which is still referred to as Bahamian Dialect) but there remain a large number of basilectal speakers. The basilect is quite distinct from the acrolect and contains most of the same features that are attributed to many of the other English-based creoles of the Caribbean and its environs. 
Bahamian has been compared to Gullah by those familiar with both, most notably Holm (1988), and it has even been classified under Gullah (presumably as a variety of the same) by Smith (1995). It should come as no surprise that the two are strikingly similar given the historical connection between the Carolinas and The Bahamas.

Saunders (1985) notes that between $1783-1785$ “...it is estimated that between 5,000 and 7,000 Loyalists and their slaves...migrated from Georgia and the Carolinas to The Bahamas". This essentially doubled the existing population. She comments on their impact saying, "the Loyalists, who brought with them relatively large numbers of slaves, affected the whole structure of the population and (vastly) expanded the slave population". She further notes, "From all accounts, it seems that most of the slaves brought in by the Loyalists were creole-born (i.e., born in the West Indies or America and not in Africa)".

Besides Gullah, Bahamian shares a number of similarities with several other English-based creoles of the Caribbean rim such as those spoken in Guyana, Belize, St. Vincent or the Virgin Islands. No matter which theory of creole genesis one subscribes to, it should be duly noted that there was a great deal of movement throughout the region. Saunders (1985) indicated that as far back as the early 18th century in The Bahamas "...the black population had increased considerably. Apparently, as the whites became wealthier from privateering, they bought more slaves. Negroes were imported from Jamaica, Guinea, Hispaniola and Barbados between 1718 and 1727".

Shilling (1978) observes a similarity of the Bahamian copula and its behaviour with that of the Guyanese Creole basilect, suggesting that "...variation in the BD copula can be accounted for if $\mathrm{BD}$ is considered to have developed from an earlier stage where copula categories were similar to those in present-day Guyanese Creole basilect." She proposes a closer link between Black Bahamian Dialect and Guyanese Creole than between BBD and Black English.

Though I originally planned to discuss each feature in detail, using the chart as a guide, I now realize that would be entirely too ambitious. Hence I will have to limit my discussion to a few brief comments. However, since this is a work in progress, further details may be added as it is refined. In fact what you see here has evolved from the combined efforts of those of us who have been teaching the various linguistics courses at The College in recent years: Anne (Albury) Lawlor, Michelle (Major) Bain and myself. Before I proceed with the feature summary I wish to acknowledge and thank the many people who like me have worked in the field gathering data: John Holm, Alison Watt Shilling, Anne (Albury) Lawlor, Michelle (Major) Bain, and countless students of theirs and mine. I have drawn my examples from their field work as well as my own. Proper attribution for each utterance should be given when this description is finalized, but for my present purposes I must beg your indulgence. 
The array of sources was overwhelming and most complicated. The utterances used for my illustrations come from the Dictionary of Bahamian English, the unpublished dissertations of Shilling (1978), Albury (1981) and Major (1993), and numerous interviews conducted by myself and all of those noted above. Suggestions for how to properly credit each source would be appreciated and details about the data can be obtained from me as I have made note of the source of each utterance.

\section{BASILECTAL FEATURES OF BAHAMIAN CREOLE ENGLISH}

While I have chosen to focus on the more basilectal features of the morpho-syntax for this paper, I should note some of the more distinctive phonological and phonotactic features for reference purposes. Like most of the English-based creoles of the Caribbean rim, Bahamian regularly substitutes the alveolar stops / $\mathrm{t} / \mathrm{and} / \mathrm{d} /$ for the interdental fricatives $/ \Theta /$ and $/ \partial /$. Less common but not unique is the regular substitution of the labio-velar glide / $\mathrm{w} /$ for the voiced labio-dental fricative / $\mathrm{v} / \mathrm{\text {. }}$ (As might be expected, the reverse takes place for many speakers as well.) Some basilectal speakers lack the voiced, palatal fricative / $\check{z}$ / entirely; others use it medially only, replacing it with the voiced, palatal affricate $/ \mathrm{j} /$. Palatalization occurs following the velar stop / $\mathrm{k} /$ and / g / when followed by a low front or central vowel. Final consonant clusters regularly reduce, particularly /-nd / , /-ld / , /-st / , /-kt /, and /-ft /. Postvocalic ' $\mathrm{r}$ ' $/-r /$ is absent for all levels of speakers with the result of an intrusive ' $r$ ' creeping in for certain words, e.g., 'surpose' for 'suppose', particular for basilectal and mesolectal speakers.

Basilectal speakers rely on fewer vowels than the mesolectal and acrolectal speakers. In some case all vowels of the standard are used but certain vowels rarely occur (e.g., the upsilon or the digraph ' $a$ '), It would seem for some speakers there is no distinction between the low front digraph ' $a$ ' and the low central ' $a$ '. Most distinctive for basilectal speech - a true marker - is the substitution of / $\partial y /$ for / $\partial r /$, so that 'first' sounds like 'foist' and 'learn' sounds like 'loin'. Not surprisingly, some speakers then replace / $\partial y$ / with / $\boldsymbol{r r} /$ so that 'foil' sounds like 'furl.' Anyone aspiring to be a news reader on the national television station ZNS would have to eliminate such pronunciations.

While there is generally a lack of contrast between / I / and / $\varepsilon /$ before and / $\mathrm{r} /$ for speakers at all levels, there is also a lack of contrast between / i / and / e / as well as / $\mathrm{u} /$ and / $\mathrm{o} /$ before the labial and alveolar nasals / $\mathrm{m} /$ and / $\mathrm{n} /$ for basilectal speakers. Thus 'seem' and 'same' would sound the "seem" (the upper vowel prevails), 'mean' and 'main' would both be "mean", and "whom" and "home" as well as "moon" and "moan" would be /hum/ and /mum/ respectively. 
There is no official orthography for Bahamian and, thus, when it is in a written form, varying techniques of eye dialect are employed depending on the writer. These devices are far from uniform - even within the same piece of writing. It would therefore be useful to try to standardize the representation so as to reflect the differences in pronunciation without having to rely on a specialized knowledge of phonetics. However, this is a matter which will have to be addressed at a later date.

What I have outlined below is a summary of some - but not all - of the more basilectal features of the morpho-syntax. I have tried to avoid those features which are more mesolectal - such as puralizing non-count nouns, e.g., furnitures, luggages, equipments - but I fear I have probably strayed in places. It is difficult to find a speaker who doesn't vary between basilectal and mesolectal speech (often within the same sentence!)

\section{TABLE}

\section{BASILECTAL FEATURES OF BAHAMIAN CREOLE ENGLISH}

\section{MORPHO-SYNTAX}

1. The Noun Phrase

A. Articles

1. $\varnothing$ Article

(Generic/Nonspecific NP)

'e cut it dan make $\emptyset$ farm.

Me ain' wan see $\varnothing$ needle an' das wha' he pullin' out.

Terry an' Preston dey bin $\emptyset$ man den.

2. Definite Article de (Presupposed-specific NP)

When de mailbag come de people load wid mail.

We de ancient people.

3. Indefinite Article a/one

I a ole woman

(Asserted-specific NP)

Cut de pain ya does have, ya does have one pain an' dat cut de pain.

[Referring to ram's horn]

B. Nouns

1. Pluralization

a. ø Plural

Me an' him does work de fiel'_.

Momma does fix bean_ in soup but I rather peas. 
b. Dem Pluralizer

(Postnominal Marker)

i. Common Nouns

ii.Proper Nouns

c. Dem Determiner

(Prenominal Marker)

d. Modifier

(Modifiers may convey

plurality)

2. Possession

a. Nouns in Juxtaposition

(Possessor + Possessed)

b. Own Marker

(Noun + own / un /)

C. Pronouns

1. Personal

a. Case

(Unmarked - varied)

b Gender

(3rd pers. sg. not

always distinguished)

c. Possession

i. Possessive Adjective (Subj. case + possessed)

ii. Possessive Pronoun

(Subj. case + own / un /)

d. Number

(Distinct 2nd pers. pl.)

2. Reflexive (Subj. case + self/sef)
De sour-dem ain' full yet.

Muh sister-dem is carry on bad

'e mussy gone ta m'cousin Isme-dem.

John-dem gone tief de man tings.

An' all a dem lil boys I does jook roun'. One a dem book is mines.

Plenty bark tree_ in de bushes dere na. All de place_ you see out dere is graves.

Dis muh sister chile.

We gwine by Sam-dem place.

Alison-own doing right now.

Das my cousin-dem own.

Dey crook we.

Me an' her just live close. [= friendship]

De nurse bring chree yard a cotton an' 'e boun' de two a me leg.

But na de date an' date, 'e on de card.

We only did leave wid [were left with] de suit on we back.

He ma from Sweden.

You-own is boys?

I know de man-dem. Was 'e oon family.

Yinna bin Old Bight, too?

All a yinna bin home.

Yinna take care yinnasef?

We is cook for wesef. 
3. Relative

(Ubiquitous what/wha')

4. Interrogative

(Bimorphemic (words

may replace SE words)

5. Postnominal Apposition

(Pronouns may duplicate subjects)

D. Adjectives

1. Inflection

a. Regularized -er/-est (Applied to all adjs. without exception).

b. Multiple Marking (More/ most + -er/-est)

2. Reduplication

(Functions as intensifier)

\section{Agreement}

(No distinction between count \& noncount nouns)
I hear 'bout one man wha' get burn up in 'e car.

Move de pot wha' de on de table quick!

What side he want me put it?

Which part he gone?

De boys-dem dey was big men.

Ole Rupert he jus' ain' lookin' too good dese days.

Dis is de beautifullest one

My memory gettin' worser an' worser.

Dis is much more better.

To my mind dis de most beautifullest.

Gyal, dis food fresh-fresh - ain'gat no seasonin' or nothin'!

Crack, conch what dey is serve to Tree Queens sweet-sweet.

How much a yinna sisters?

He have too much bad ways.

II. The Verb Phrase

A. The Unmarked Verb

1. Non-past: Stative

I tink he over in de udder garden. My nex' aunty live jus' about two block from here.

2. Past: Nonstative

When we reach out ta de corner a puff a win' take me, I haddy grab hol' Glen.

I spend so much a money ta de doctor 'til I decide ta go ta Dr. Jesus. 
3.Past/Nonpast: Passive

4. Verb Derived Adjectives

B. The Copula

1. Equative be NP)

a. Non-past/Present (commonly is, sometimes are, rarely a)

b. Past/Anterior (bin/was usually mark past, sometimes is occurs)

2. Descriptive be Adjectives)

a. Non-past/Present ( ${ }^{-}$marking prevails before statives)

b. Past/Anterior (did/bin)

3. Locative be (_Adverbs of place)

a. Non-past/Present (generally $\varnothing$ marking or occasionally de)

b. Past/Anterior (bin prevails, = simple past and past perfect)
Acklins is a poor place. Ain' much a money make here.

Das gobmen(t) dock, dat buil' las year.

Dey servin' crack conch an' boil fish. You mouth run like parch benny.

I was a Miller but I's Mistress [Mrs.]

Rolle. But me husban' dead.

Dese boys does live wit her but dis a her home.

Dey bin man den.

Only ting (sh)e was a stranger.

[Not her birth mother]

Muh husban' is (was) a white man.

Dey say I $\varnothing$ ole, say dey ain’ gatty bodder wid me. I done ole!

Some people $\varnothing$ black, some $\varnothing$ clear.

I had husban(d). 'e was good an' ain' was good. I ketch hell.

No, sir, bread bin so small I couldn't give you none.

He did hungry.

One-one $\varnothing$ here now.

An' dey all de udder res(t) $\varnothing$ in Freeport All $\varnothing$ in Freeport.

Two on 'em de here now.

I bin dere las' year an' I bin dere de year before las'.

I bin down in ya daddy house. 
C. Adjectives as Predicators (Occur unmarked / with TMA Markers)

1. Stative

When de wedder $\varnothing$ good 'e go fishin'.

The sisal when it done it does be white.

Oh yeah, he was a good on it.

[The concertina]

2. Intransitive

Muh mammy had chree boy, one dead a baby.

Plenty grave...dat done full up.

I thought papa couldn't sick.

3. Transitive/Causative

He get hot water, he hot it.

She gern put ya in de tub an' she boil dat bucket a bat(h) an' she col' de bat(h)

D. Serial Verbs (Juxtaposed main verbs)

I leave dat come down here after he died.

(Sh)e stay make a man an' woman, an'

'e had shop an all like dat.

Well, in my young days I useta haddy go in de bush pick wood cook in de kitchen bake bread.

E. TMA Markers

1. Anterior Tense (bin/did mark earlier time, including passives)

He got sick. Yeah, -errybody did like him. He did name Harley.

To be trutful, I's one a dem mysef, didn(t) particular wit school

Yeah, I bin like school an' I like church til now.

Dese bin make fa foot but ya know where dey get vehicle, vehicle dig dem out. [footpaths] 
2. Progressive Aspect

a. Independent Vin (g) (bin/did mark earlier time including passives)

b. TMA Marked Vin(g) (TMA markers + Vin')

c. TMA Marked V (Rare: a/de + V stem)

3. Habital Aspects

a. Uninflected be (Be marks habitual for both past \& nonpast

b. Nonpast

(does, is, -is $+V$ )

c. Anterior (usually useta $+\mathrm{V}$, sometimes does/is/ $-\mathrm{s}+\mathrm{V}$ )
I $ø$ takin' care of dem right now.

We $ø$ watchin'de storm.

My chirren, we bin laughin' cause we ain' know wha' storm bin.

He was sailin' on de ship, ya know.

Joy say "You shoulda be livin' close by."

I de wait on dem.

When I should go I didn(t) go, mind, I a duck it, I a duck.

When dey come in...people be row right up.

Yeah, sometimes 'e takes weeks cause if it be calm, ya know, de sail jus' blow dis way an' dat.

Oh sometime you be lucky...we had a lot of boat den.

All dey does be in de pon(d), dem wha' does set over water. [Referring to muckleberry bushes]

...an' all dem little boys I does jook roun'. [Referring to spading of seedlings]

I is drink aloe too.

An' dem olden days people useta make de castor oil outta dose barbs ya see out here.

Well sometimes I hear dey useta gatty sail like sailin' boat, In dem days dere wasn(t) no motor.

Dey is go up to Green Turtle Cay, if dere was anyting, ya go dere if ya wan $(\mathrm{t})$ see a doctor, ya go up to Green Turtle Cay. 
4. Completive Aspect

a. Nonpast $($ done $+V)$

b. Anterior (did done $+V$; rare: bin done $+V$ )

5.Irrealis

a. Future (go/ga/ger/gon/guh)

b. Conditional

(Anterior + go $+\mathrm{V}$ or woulda $+V$ )

c. Hypothetical $($ bin $+V)$

\section{F. Complementizers}

1. for $/$ fa/fer $/$ fo $+V$

2. Ø Marked Infinitive. (bare stem)
When ya done peel 'em ya cut 'em in half.

After she done bat(h) you an' she press you up she turn you loose.

Time as I reach de store she did even done buy de dress.

De spongin' at dat time did done dead out.

I could tell when anyting ga happen. When ya see muh shoulder drop, das something serious.

You ever see cat charm bird ta ketch um? When de cat ga charm um...

An' I tell dem de dream I had an' dey tell me wha' di(d) go happen. If everybody woulda be like me this would be a beautiful world.

You ain' bin like my days. In my days, when October time, if ain' meet ya wit food in ya house, it carry you right out so.

He woulda bin vex with me if I bin ever catch him.

Learn me fa talk. Learn muh fa talk.

Dey want me fa vote fa de PLP.

[Wrecked her home for not doing so.] He don't want fer carry you.

He useta like $\varnothing$ gamble.

'e useta mistreat me. See, he's a man like $\varnothing$ bruise. 


\section{NOTES}

1. This paper was presented at the 11th Biennial Conference of the Society for Caribbean Linguistics at St. Maarten, N.A., August 14-17, 1996.

2. The following definitions are taken from the Dictionary of Bahamian English by John A. Holm with Alison Watt Shilling.

Creole - any language with a pidgin in its ancestry, especially those mixed languages spoken by creole or New World Africans which seem to be European languages reorganized along African lines (e.g. Haitian French, Bahamian English, Papiamentu, Gullah etc.).

Creole continuum - in countries where creole languages co-exist with their European lexical-source language as the official medium, a spectrum of speech varieties ranging from those farthest from the standard (basilect) to those closest (acrolect).

Decreolization - the process in a creole continuum caused by the influence of the acrolect on the mesolect, in which overt creole features are progressively avoided in favour of those of the standard variety.

Acrolect - (in a creole continuum) the variety of speech closest to the standard.cf. Basilect, Mesolect.

Basilect - (in a creole continuum) the variety of speech farthest from the standard cf. Acrolect, Mesolect.

Mesolect - (in a creole continuum the intermediate varieties of a language between Basilect and Aerolect.

Pidgin - a contact language used between two groups which have no language in common, especially a simplified variety of one group's language which has become somewhat stabilized for some special purpose, e.g. trade.

\section{REFERENCES}

Albury, Anne. 1981. "The Status of the -ed Suffix in Black Bahamian English." Unpublished M.A. thesis, University College, London.

Albury, Paul. 1975. The Story of The Bahamas. Macmillan Caribbean.

Alleyne, Mervyn C. 1971. "Acculturation and the culture matrix of creolization." Pidginization and Creolization of Languages. Ed. Dell Hymes. London: Cambridge University Press. 169-186. 
. 1980. Comparative Afro-American. Ann Arbor: Karoma.

Bain, Michelle V. (Major). 1995. "English Language teaching and Bahamian Dialect interference: some perspectives." At Random, VI. Nassau: The College of The Bahamas, Humanities Division.

Bickerton, Derek. 1981. Roots of Language. Ann Arbor: Karoma.

Christie, Pauline. 1991. "Modality in Jamaican Creole." Verb Phrase Patterns in Black. English and Creole. Eds. Walter F. Edwards and Donald Winford. Detroit: Wayne State University Press, 223-239.

Edwards, Walter F. 1991. "A comparative description of Guyanese Creole and Black English preverbal aspect marker don." Verb Phrase Patterns in Black English and Creole. Eds. Walter F. Edwards and Donald Winford. Detroit: Wayne State University Press, 240-255.

Holm, John A. 1980. "African features in white Bahamian English." English Worldwide. 1(1): 46-65.

. 1983. "On the relationship of Gullah and Bahamian." American Speech 58: $303-318$.

. 1988. Pidgins and Creoles. Vol.1: Theory and Structure. London: Cambridge University Press.

Holm, John A. and Alison Watt Shilling. 1982. Dictionary of Bahamian English. Cold Spring, NY: Lexik House.

Lawlor, Anne. 1986. "An investigation in progress: past forms and their functions in Bahamian English..." Paper presented at the Conference of the Society for Caribbean Linguistics, Trinidad.

. 1988. "Bahamian English or Bahamian Creole?: a sociohistorical investigation." Paper presented at the Conference of the Society for Caribbean Linguistics, Nassau.

Major, Michelle V. 1993. "Some Non-Standard Features of College Writing: Evidence for a Second Dialect Approach to English Language in The Bahamas." Unpublished M.A thesis. Southern Illinois University at Carbondale.

McWhorter, John H. 1995. "Sisters under the skin: a case for genetic relationship between the Atlantic English-based creoles." Journal of Pidgin and Creole Linguistics 10 (2), 289-333. 
Mufwene, Salikoko S. 1996. "Creole genesis: a population genetics perspective." Caribbean Language Issues: Old and New. Ed. Pauline Christie, Kingston: The Press University of the West Indies, 163-196.

Parsons, Elsie Clews. 1918. Folk-Tales of Andros Island, Bahamas. Memoirs of the American Folklore Society 13.

Pollard, Velma. 1993. From Jamaican Creole to Standard English: A Handbook for Teachers, New York: Caribbean Research Centre, Medgar Evers College (CUNY).

Roberts, Peter A. 1988. West Indians and Their Language. London: Cambridge University Press.

Romaine, Suzanne. 1988. Pidgin and Creole Languages. London: Longman.

Saunders, Gail D. 1985. Slavery in The Bahamas: 1648-1838. Nassau: The Nassau Guardian.

School Atlas of The Commonwealth of The Bahamas. 1992. Eds. Neil Sealey and E. John Burrows. London: Longman.

Seuren, Peter. 1991. "The defination of serial verbs." Development and Structures of Creole Languages: Essays in Honor of Derek Bickerton. Eds. Frank Byrne and Thom Huebner. Amsterdam: John Benjamins, 193-205.

Shilling, Allison Watt. 1978. "Some Non-Standard Features of Bahamian Dialect Syntax." Unpublished Ph.D. thesis, University of Hawaii.

Smith, Norval. 1995. "An annotated list of creoles, pidgins, and mixed languages." Pidgins and Creoles: An Introduction. Eds. Jacques Arends, Peter Muysken, and Norval Smith. Amsterdam: John Benjamins Publishers, 331-374.

Winford, Donald. 1991. "The passive in Caribbean English creole." Verb Phrase Patterns in Black English and Creole. Ed. Walter F. Edwards and Donald Winford. Detroit: Wayne State University Press 256-282. 


\section{AUTHOR}

Janet L. Donnelly is a Senior Lecturer and Assistant Chairperson in the Humanities Division of The College of The Bahamas. An experienced lecturer of college level English Language and Linguistics, since joining The College faculty twenty years ago she has coordinated programmes in these disciplines.

Ms. Donnelly's qualifications in Linguistics at both the Bachelor and Masters levels were earned at State University of New York at Buffalo (SUNYAB). Her research interest continues to be in the area of Bahamian Creole English.

She is a member of several professional organizations including the Society for Caribbean Linguistics (SCL), the Society for Pidgin and Creole Linguistics (SPCL) and the Linguistic Society of America (LSA). 